\title{
LA RESPUESTA DEL DERECHO NATURAL CLÁSICO A LOS DESAFÍOS DEL SIGLO XXI
}

\author{
The classic Natural Law response to the challenges of the XXI century
}

La classica risposta del Diritto Naturale alle sfide del $21^{\circ}$ secolo

Carlos R. Sanz ${ }^{1}$

\begin{abstract}
Para citar este artículo:
Sanz, C.R. (2020). "La respuesta del Derecho Natural clásico a los desafíos del siglo XXI”. Prudentia Iuris, N. Aniversario, pp. 19-29. DOI: https://doi.org/10.46553/prudentia.aniversario.2020.pp.19-29
\end{abstract}

Resumen: El presente texto aborda los efectos producidos en la cultura y la tradición de occidente y en la Argentina por la "de-construcción" de la posmodernidad. Se advierte no sólo el desvío del fin de los dirigentes y su apetito de poder, sino que también se contempla a las nuevas generaciones que renegando de la tradición terminarán en la anarquía o sujetos al aparato de poder. De allí, nace la necesidad de relanzar el legado de la tradición, lo que ha sido llamado el "Derecho Natural clásico". Siendo la educación, la entrega de las herramientas para hacer la valoración del pasado y del presente y de organizar el futuro, se busca responder ¿qué derecho, qué códigos y qué enseñanza sobre lo justo y lo injusto puede aportar nuestra facultad?

Palabras clave: Derecho Natural; Posmodernidad; Siglo XXI; Justo natural; Justo positivo; Educación.

1 Reproducimos, por su importancia, el texto publicado por el Dr. Carlos Raúl Sanz: "La respuesta del Derecho Natural clásico a los desafíos del siglo XXI. Sólo se construye del otro lado de la decepción", en La codificación: raíces y prospectiva. ¿Qué derecho, qué códigos, qué enseñanza?, T. III, Buenos Aires, Ed. El Derecho (colección Prudentia Iuris), 2005, ISBN 950-523-346-9, pp. 21/33. 
Abstract: This text addresses the effects produced in the culture and tradition of the West and in Argentina by the "de-construction" of postmodernity. Not only the deviation of the end of the leaders and their appetite for power is noticed, but also the new generations that denying the tradition will end up in anarchy or subject to the power apparatus. Hence, the need arises to relaunch the legacy of tradition, what has been called "classical Natural Law". Being education, the delivery of the tools to make the assessment of the past and the present and to organize the future, it seeks to answer what right, what codes and what teaching about what is fair and unfair can our faculty provide?

Keywords: Natural Law; Postmodernity; XXI century; Just natural; Fair positive; Education.

Sommario: Questo testo affronta gli effetti prodotti nella cultura e nella tradizione dell'Occidente e in Argentina dalla "decostruzione" della postmodernità. Non solo si nota la deviazione della fine dei leader e la loro fame di potere, ma anche le nuove generazioni che negando la tradizione finiranno nell'anarchia o sottoposte all'apparato del potere. Da qui la necessità di rilanciare l'eredità della tradizione, quella che è stata chiamata "Legge Naturale classica". Essendo educazione, la consegna degli strumenti per fare la valutazione del passato e del presente e per organizzare il futuro, cerca di rispondere quale diritto, quali codici e quale insegnamento su ciò che è giusto e ingiusto può fornire la nostra facoltà?

Parole chiave: Diritto Naturale; Postmodernità; XXI secolo; Fiera naturale; Fiera positiva; Educazione.

\section{1) Introducción}

Difícil cuestión es la que propongo abordar. Se trata nada menos que de aportar un intento de respuesta a los interrogantes básicos del mundo jurídico, luego del desastre producido, en la cultura y tradición de Occidente, por la "de-construcción" de la posmodernidad, por la violencia, por la existencia de nuevos fenómenos jurídicos a consecuencia de la globalización -o mundialización, o americanización- y -en la Argentina- por la implosión económica generada por la usura, el desgobierno y la rapiña.

Frente al siglo XXI, ¿qué derecho, qué códigos y qué enseñanza sobre lo justo y lo injusto puede aportar nuestra facultad? ¿La simple vuelta al esquema del racionalismo de los siglos XVIII y XIX? ¿La soberbia crítica de los intelectuales ante las iniquidades del statu quo, para demostrar que se 
ha equivocado el rumbo -en algún punto de la carretera- y que ahora no sabemos cómo recomponer la situación fuera del nihilismo y el esoterismo individual, la violencia en el manipuleo de las relaciones humanas o los largos enunciados de las sentencias que sirven para un fregado o para un cocido? O -en el mejor de los casos- ¿la huida al yermo como deserción de la polis; convertida ésta en escuela de torpezas e iniquidades y no ya en andarivel de las virtudes?

$\mathrm{El}$ apetito de poder de los dirigentes -de todos los niveles- y la perpetuación en los cargos han ido generando una oligarquía política y gremial que, a los desatinos comerciales, les ha agregado un matiz de poder feudal, donde el voto democrático termina siendo una presa en manos de los "aparatos" territoriales de los dueños del poder. Pero -y he allí el absurdo- las nuevas generaciones de jóvenes, al abominar de la tradición, terminan siendo oleadas de nuevos bárbaros que -a la larga- terminarían o en la anarquía o en la sujeción a los mismos aparatos de poder, si no es que, desde el vamos, aspiran a ser miembros de las mismas oligarquías de las que son prebendarios.

\section{2) Hacia una caracterización de nuestro tiempo}

Como punto de partida, con la provisoriedad que un diagnóstico de la situación puede tener, dos ideas capitales rondan ante nosotros como ejes de la convivencia: la mentira -doble discurso se suele decir-y la desmesura -en cada uno de los ámbitos de la acción.

Esas falacias engendran cadenas de sofismas como caricatura de los saberes prácticos y atomización micrónica en los saberes especulativos. Lo cual ya no es querella de intelectuales, sino que se fija en formas concretas del despotismo, discriminación y violencia en las diversas formas que puede asumir la "convivencia" social e institucional. Brutalidad en el trato, hegemonía en las relaciones interpersonales, utilización de la técnica para las autocracias, que el igualitarismo de la revolución hace materia disponible para los más ignorantes y osados; puro voluntarismo en el gobierno de los cuerpos intermedios y en el "activismo" de los jueces.

Cualquiera sea la valoración que se haga, lo cierto es que han cambiado -en el mundo y en el país- las reglas de juego de la pax burguesa.

Nuevos fenómenos abarcan la escena: un regreso del Derecho judicial en el contexto del mercado, pero con un matiz agnóstico, que significa consagrar el comportamiento que se juzga correcto a la luz de la práctica ordinaria de los miembros del grupo dominante. La sociología -como descripción de lo que sucede- ha sustituido a la ética. Conforme a un parámetro puesto por el poder supranacional que, en el caso de Europa, fija la Corte de Estras- 
burgo de acuerdo al interés económico de la Comunidad y en los países como el nuestro la cultura de la imagen, el poder de los medios de comunicación y los intereses que lo manejan y lucran con ellos.

La sociología -juridizando lo que sucede- ha preterido al Derecho -que trata de ordenar a las personas, cosas y grupos sociales intermedios-; ese esfuerzo secular por instaurar lo justo lo ha revestido de la calificación indecorosa y despreciable de fundamentalismo. Lo que "sucede" según la voluntad del poderoso ha derribado a la juridicidad, lo debido, la cadena de equilibrios de lo suyo de cada quien, cuyo resultado es la paz.

Se da cita un Derecho de fondo mínimo, con un aumento frondoso de regulaciones administrativas que se tornan un eco de los poderes económicos (así se habla del derecho de textura abierta), como sucede con las exigencias del Banco Mundial, del FMI y de otras instituciones. Estos órganos del poder económico mundial se sirven de los Estados y de las categorías jurídicas nacionales para llevar a la práctica sus decisiones globales.

Todo ello lleva a un auge del contrato predispuesto y del Derecho de Daños, en la esfera interna de los Estados remanentes, sin dejar de advertir la injerencia de las grandes potencias en materia de incumbencia humanitaria, poblacional, moral y de seguridad global. El peso de los mercados financieros, el intento de control de la criminalidad global y las formas alternativas de resolución de conflictos van generando normas e instituciones al margen del Derecho Privado y del Estado nacional; como la difusión en internet y de la televisión hace cada vez mayor su injerencia en la tarea educativa.

La espontaneidad inorgánica de la sociedad civil presiona contra el orden de la legalidad, en medio del desprestigio bien ganado de los Parlamentos y Tribunales, lo cual tiene como resultado un divorcio entre la ley y lo justo y entre la sentencia y la ley.

Entre nosotros, la reforma constitucional de 1994 -sin por ello negar algunos aciertos- surgió de un pacto que todos conocemos, y sirvió -al margen del objetivo primario- para que tanto el oficialismo como la oposición en una rotación bipartidista que parece agonizar, pero que no muere- vivan del presupuesto.

Las instituciones creadas con la reforma han manifestado, a su tiempo, la nota prebendaria y disolvente.

¿Qué ha producido la autonomía de la Capital? Obstáculos para el mantenimiento del orden y la limpieza de la ciudad -en lo externo- e irrescatables instituciones políticas al servicio de la contracepción, de la liquidación de la familia única, indisoluble, monogámica y heterosexual y se avecina una embestida a favor del aborto. Política de "género", se dice con eufemismo, como si el género humano pudiera ser otra cosa que la sumatoria de hombres y mujeres. 
¿Qué cambio ha producido en la Justicia el Consejo de la Magistratura, salvo alguna buena designación de excepción que no era extraña con anterioridad? Lo que sí ha generado es una nueva y frondosa burocracia -solventada con nuestros impuestos- que hasta hace añorar las formas igualmente torpes, pero más baratas del pasado. A ella se han unido otras más a nivel de la Administración y del Parlamento. Enfrentado con la Corte Suprema de Justicia, con los Tribunales ordinarios y cómplice del silencio, es un claro ejemplo de la lucha de todos contra todos en la que se ha canalizado el furor y la frustración argentina.

El Poder Ejecutivo bate todos los récords en materia de legislación de urgencia, mientras que un Poder Judicial adormecido deja pasar, o incluso incentiva, la acción de los grupos de opinión en beneficio de un statu quo. El esquema cívico-cultural general lleva a la vía muerta en la que estamos... De allí que estas Terceras Jornadas nos encuentran del otro lado de las ilusiones que -muchos de los que están aquí- hemos tenido. Enteros y dedicados a construir, a fundar, a mantener las murallas morales de la ciudad; esa es la coyuntura en la cual colocamos el Derecho Natural clásico en una posición inexcusable que, sin duda, podrá intentar descalificarse como "ingenua". Pero ¿no ha llegado el momento de recordar lo elemental? Que dos más dos es cuatro y que no se puede construir un país sin dirigentes preocupados por el bien común y con ciudadanos con vocación de rapiña, como el arquetipo del "viejo Vizcacha".

\section{3) ¿Qué es el Derecho en el pensamiento clásico?}

Cuando hablamos del Derecho Natural clásico no hablamos de la "ley natural" sino que el oficio de descubrir el Derecho -en los mundos agonales del "poder" de la política y del "haber" de los mercados- es una tarea propia de laicos. Subalternada si se quiere a muchos otros saberes, incluso a la teología por sus fines y principios, pero fundamentalmente obra de jurisprudentes.

Cuando hablamos del Derecho Natural clásico tampoco hablamos de ese derecho racional y matemáticamente deductivo del que se hablaba en los círculos intelectuales europeos al tiempo de la codificación decimonónica, que no resulta más que el devengamiento de los intereses del cartesianismo católico y del gran capital supérstite de la cristiandad medieval europea.

Cuando hablamos del Derecho Natural clásico tampoco estamos hablando de los "derechos naturales" que pueblan nuestras modernísimas constituciones. Las libertades de la Declaración de 1789 suponían un Estado existente al que se exige el respeto de algunas regiones interiores supuestamente excluidas del pacto social, o "libertades", si se quiere llamar 
así. El problema con este mito estoico que reflotan los filósofos modernos como Hobbes, Rousseau, Locke, etcétera, ¿dónde queda si el contrato social no ha existido? Es una teoría indemostrable. Una teoría que nada tiene que ver con la realidad es una mala teoría y debe abandonarse. Pero el asunto es peor si estos Derechos Naturales aparecen como expresiones del individuo aislado, como sucede con la visión contemporánea, en la ordenación del hombre a su fin, con-fundiéndose el orden ético y antropológico con una cadena de llamados "derechos" o, peor aún, llevados a la noción de "garantías", como en el Estatuto orgánico de esta Ciudad de Buenos Aires.

Cuando hablamos de "pensamiento clásico" estamos apuntando al modo de entender lo justo y lo injusto a partir de lo que son las propias cosas sociales. Es esta línea de interpretación la que encontramos en la noción de to dikaion que vemos en el Libro V de la Ética Nicomáquea, de Aristóteles, la forma de comprender esos temas en el Derecho pretoriano romano, la idea del jus sive justum que Santo Tomás expone en la q. 57 de la II-IIae de la Summa Theologiae, en el Derecho culto del medioevo y en los más notables juristas del antiguo régimen, renacido hoy como exigencia de una realidad que amenaza con aplastarnos.

Este "pensamiento clásico" se contrapone, ante todo, al llamado "pensamiento moderno" que, pese a sus raíces medievales, aflora con la constelación de filósofos racionalistas a partir de los siglos XVI, XVII y XVIII, puestos a proponer estructuras políticas y sociales, y tiene su expresión jurídica más notable en las declaraciones de derechos que se elaboran desde la Revolución de 1789.

Mientras que el pensamiento clásico considera la realidad como una urdimbre de relaciones armoniosas -que en cristiano nos lleva a hablar del orden de la creación y que los griegos llamaban simplemente "cosmos"-, los modernos han ido atomizando el conocimiento de las cosas.

Así, en el caso de las cosas políticas, la ciudad, la república, el orden político ya no serán vistos y explicados como un "microcosmos" en el cual habitan las familias y donde ha de crecer la virtud, en consonancia con el orden del todo (visión que intentaba plasmarse desde el ritual de fundación de ciudades y no un conglomerado de átomos). Individuos convivientes en estado de guerra, que huyen de ese mítico estado basal, que es el "estado de naturaleza", mediante el artificio de un supuesto contrato social que origina el poder ilimitado de Leviatán y cuyo dominio absoluto (independiente del pacto) impone una ley -acto de puro poder-que al generar "potestades subjetivas individuales" ordena la convivencia de manera tal que se salve un mínimo de libertad (a lo que se llamará "derechos naturales") para obtener un máximo de seguridad.

Mientras que para los clásicos, el Derecho es la parte que corresponde a cada quien en el marco social (parte que incluye cargas y beneficios), para 
los modernos, el Derecho es sólo prerrogativa subjetiva, individual. Facultas moralis agendi, potestad para exigir -a la comunidad, al poder político- que se le otorgue un sumun que ya no es parte de un todo, sino consagración de anhelos, aspiraciones, ilusiones e intereses individuales. Su derecho son sus derechos y sus derechos se van elaborando y superponiendo a medida que crecen los aspectos hedonistas y desjerarquizados de la cultura.

Si la declaración de 1789 implica un catálogo acotado de aspiraciones y garantías, ya las constituciones del siglo XIX amplían su marco -como nuestro art. 14 de la Constitución- para convertirse - poco a poco- en cataratas de ilusiones en las llamadas constituciones sociales posteriores a la Segunda Guerra Mundial -derechos del trabajador, de la ancianidad, etc.-, y llegar con sus torrentes normativos a esos llamados derechos de tercera generación, en boga a partir de los años noventa. Esas normas de las que es un arquetipo el Estatuto Orgánico de la Ciudad de Buenos Aires, o de los grupos de presión política escudados en los human rights, casi hegemónicos en esta etapa política de la patria.

Es aquí donde la recordación de Napoleón coincide con nuestros males. Pues ha sido Napoleón Bonaparte y su ciclo cultural quienes hicieron de una Francia desbocada, sangrienta, expropiada y martirizada por la Revolución de los derechos y las guillotinas, y de una Francia al borde de la disolución nacional, la Francia moderna señora de sus destinos. Y fue su Código Civil la herramienta adecuada para poner paz en las familias y en las instituciones.

\section{4) En síntesis}

Si el Derecho es la parte, la cosa que es propia como conjunto de cargas y beneficios de quienes conviven en la sociedad, hablando propiamente, no es ni la ley, ni la potestad subjetiva como resulta del uso común.

Es el descubrimiento de lo justo y lo injusto (ius es opuesto a iniuria) por la inteligencia, la prudencia permite justicia -como voluntad constante y perpetua de reconocer a cada uno su ius, su parte, su derecho. De allí que pueda decirse con propiedad que el Derecho es objeto de la justicia; el Derecho especifica -hace propia de una especie- a la justicia. Esto es lo que Santo Tomás muestra en la q. 57 de la II IIae. de la Suma Teológica. El Derecho es aquello a lo que apunta la justicia y por ello hace a ésta una virtud específica, distinta a las demás. Porque el Derecho -hablando con propiedad-es ipsa res iusta: es la propia cosa justa. Aquello que se ajusta a otro (por eso se debe) según algún modo de igualdad -directa o proporcional. De allí que sea necesario, primero, determinar intelectualmente qué es el 
Derecho para, luego, advertir la edificación y existencia de la virtud. Todo ello planteando el tema en términos de razón natural.

¿Puede llamarse Derecho a las "potestades”? ¿Puede llamarse Derecho a las normas? Simplemente, no. Pues el Derecho es la proporción justa en función de la cual existe la regula iuris y en función de la cual quien reclama tiene una facultad a que se reconozca y consagre judicialmente lo que es suyo propio (actio). También ha de ser primero el ius para edificar la ley, para dar lugar a la actio judicial y para configurar -junto con otros casosun orden social justo, como enseñaba Llambías memorando a Renard.

Así considerado el Derecho, "esto justo" existe en diversos niveles. Existe un iustum que se da en los cambios y otro iustum que se da en las distribuciones políticas. Existe un iustum que surge ex ipsa natura rei y otro iustum que es puesto - positivo. Así, cabe hablar de un iustum conmutativo y de otro distributivo; hay un Derecho Natural que es la relación social justa -como sucede con el equilibrio en los cambios-y otro Derecho Positivo -que es la norma.

Es menester insistir entre el ius nacido ex ipsa natura rei -de la naturaleza de las cosas- y el ius puesto, el ius positivo. Puesto, por el contrario, por la ley y por los convenios sociales (aspecto hoy no tan desconocido si vemos los forcejeos que se hacen frente a la ley de presupuesto y al reparto de la coparticipación federal) y habitual en tiempos medievales, en las relaciones entre estamentos y de estos con los señores.

Si bien existió un abuso, tanto en el Iluminismo como en la Escolástica, sobre el tema del Derecho Natural, resulta clara su relación. En el Iluminismo se llamó "Derecho Natural" a una serie de principios racionales prácticos -en el sentido de que impulsan a la acción- que se pensaron como punto de partida para que luego, mediante el uso racional de la deducción, se fueran sacando conclusiones cada vez más cercanas a la realidad. Así, de los tres principios clásicos de Grocio - cumplir con la palabra empeñada, abstenerse de la propiedad de otro y reparar los daños producidos por culpa- se pretendió sacar, por vía de conclusión, verdaderos códigos de "Derecho Natural". También la Escolástica -y la escolástica hispano-americana- pretendió un Derecho Natural que fuera conclusión de principios conocidos por los teólogos a partir de ciertos principios de la ley eterna.

Así, el "Derecho Natural" terminó convertido en ley natural, ley racional o norma moral revestida de coacción pública por el poder temporal.

Es en ese contexto y a través de esas claves que aparece el fenómeno de la codificación, presentado no ya como una consolidación o sistematización de normas positivas, sino como una construcción autónoma, autosuficiente, con absoluta coherencia. Expresión del legislador, como vocero de una supuesta "voluntad general", surgida de la concurrencia cívica y organizada "more geométrico". 
Hoy, todo ese andamiaje de mitos y creencias es insostenible. No existe el hipotético "estado de naturaleza" -mito estoico, renovado en la modernidad-, ni las relaciones sociales son fruto de un contrato social. Ni la ley concreta es expresión de una razón universal -que suponía conocer el filósofo o el teólogo-, ni una voluntad cívica expresada por los Parlamentos y aplicada por los jueces.

La crítica de la posmodernidad, en este sentido, ha sido sanamente iconoclasta en su fase destructiva; el problema es que, al derribar los mitos del Estado iluminista, no ha ofrecido, en cambio, un sistema de vigencias sociales realistas y veraces que sirviera de sostén a la convivencia, que termina siendo para estas corrientes rupturistas un "hecho" o una "construcción" racional sin que medien "criterios objetivos" de bien y de mal, de verdad y falsedad, de justo o de injusto. Así, esta cultura posiluminista termina dejando a las comunidades sin conciencia histórica de pertenencia cultural, y sometidas a fuerzas económicas poderosísimas: el mercado, la opinión de los medios, el interés corporativo de los políticos y la mera voluntad de los jueces y mandatarios sociales. Esto es, retomando el tema sofístico de que la justicia es la voluntad del más fuerte.

De allí, en medio del yermo en que nos ha dejado la "de-construcción" de la posmodernidad, nace la necesidad de relanzar el legado de la tradición, el legado de lo que hemos llamado el "Derecho Natural clásico".

La educación es, precisamente, la entrega de las herramientas para hacer la valoración del pasado y del presente y de organizar el futuro. Entonces, no cabe pensarse en una educación a-valorativa; puramente técnica, aséptica axiológicamente.

La sociedad en la que nacemos tiene una determinada estructura política. Cada nación tiene una historia y una trayectoria, en la cual el pasado determina el presente y la lanza hacia el futuro.

La revolución, como ruptura con el pasado, no existe. Los hombres que hacen las llamadas revoluciones son hombres con la cultura del pasado y, superado el estado de inestabilidad, las sociedades siguen su curso sin grandes variaciones. Si el principio aristotélico nos dice natura non facit saltus, esto también se da en la naturaleza de las cosas sociales. La Revolución Francesa terminó en Napoleón, luego de un lapso de desconcierto. La Revolución Rusa contra los zares terminó en Stalin y luego en la disgregación del imperio a la espera de una nueva forma de grandeza.

No es muy difícil suponer en qué terminará el Imperio americano, con miras de orden universal. Siempre habrá multiplicidad de pobres y marginados que no encontrarán lugar en el mundo de los preferidos y -a la largaproducirán la ruptura de las estructuras que les impiden el acceso. De allí, la importancia de ver con claridad la peculiaridad cultural de las naciones, de organizar redes de integración social, la explotación racional y susten- 
table de los recursos naturales y sistemas educativos que incorporen a las nuevas generaciones al contexto de la cultura. Nuevas generaciones que, de no proceder con prudencia, pagarán muy caro su soberbia, pues la madurez no es una mera acumulación cronológica de años, sino la suma de sapiencias que forman la conciencia de una cultura.

La nación soberana, integrada en el mundo -nación más o menos ampliada en función de los derroteros históricos-, pareciera hoy el entorno más amable en el cual puede desarrollarse una familia y educar a los hijos. La ruptura del tejido social ha llevado a las anarquías, que vemos no sólo aquí sino en todo el mundo. La nación soberana de la modernidad, integrada al universo mundo, parece también el entorno adecuado donde fructifique la maduración y referencia religiosa que -como un hecho, y hecho de gran trascendencia- consiste en la vocación humana radical de buscar a Dios. Aquí juega un importante papel la educación, que puede favorecer esta búsqueda, bloquearla o desviarla hacia otros absolutos, como son hoy los integrismos religiosos o el consumismo desenfrenado.

Esa nación, así configurada, tendrá o bien estructuras que favorezcan la solidez de las familias y el crecimiento armónico de sus ciudadanos, o bien formas de perdición de las generaciones. Es aquí donde aparece el fenómeno de las leyes y de los códigos.

Con ello retomamos una idea que dejamos en suspenso: la ley no crea la sociedad -aunque la robustece-, la ley no crea la virtud -pero puede favorecerla o perjudicarla-, pero la ley no puede decir que es bueno lo malo para el destino del hombre, que algo injusto no lo es.

Por cierto que lo "justo natural" no puede agotar las posibilidades históricas y culturales de una sociedad, pero también es cierto que lo justo puesto, lo justo "positivo", no se puede edificar sobre la arbitrariedad, la violencia, la iniquidad y la exclusión.

Es aquí donde el Derecho Natural clásico, la prudencia de la tradición occidental, puede decir una palabra a nuestra cultura y a nuestro destino.

El Derecho Natural clásico del que hablamos es el que busca reflejar en los asuntos humanos el orden del "cosmos" (la creación en cristiano) y hacer de la Ciudad una entidad ordenada que ayude e impulse a los hombres a vivir en la virtud, en la amistad cívica (como lo entendían los antiguos) y les posibilite buscar a Dios, el sentido de su vida y de su muerte.

El Derecho Natural clásico entiende el Derecho como la mejor disposición posible, en un tiempo y en un espacio determinados, de los grupos sociales y de los hombres que los conforman y que tiene como resultado la paz social.

El Derecho Natural clásico ve el Derecho como proportio, como analogon, como la mejor forma de comprender los elementos reales que conforman el mundo social. No es una ideología, no es una utopía, ni es una 
quimera. Enseña que quienes gobiernan y legislan tienen la obligación de ordenar su gestión hacia el bien común y que quienes administran justicia deben mantener las "partes" fijadas en el reparto de cargas y beneficios que da una república, perfeccionando y singularizando, mediante la prudencia y la equidad, aquello que es propio de cada quien.

Estas nociones básicas exigen la precisión del Derecho puesto -o positivo- que debe afinar hic et nunc aquellas pautas mediante normas justas y contratos equitativos para cuya vigilancia y reencauzamientos están los jueces que cuentan con el consejo de la doctrina de los justos y con el ejemplo de los que los han precedido.

El Derecho Natural clásico no ha tenido la petulancia de pretender que las leyes agoten la expresión de lo justo. Allí están en conjunción con ellas las tradiciones, los convenios, la cultura, la moral y la consideración del fin último del hombre.

Esto es lo que buscamos enseñar en nuestra facultad y un reflejo de ello intentamos transmitir a las jóvenes generaciones, pues entendemos que, sin perjuicio de estar abiertos a las nuevas ideas y a las nuevas realidades, existe un núcleo de doctrina innegociable: la vida, el matrimonio, el ámbito familiar, el ámbito de la fe y la esperanza de la patria venidera. Esta es la tradición que hemos recibido, esta es la tradición a la que hemos tratado de ser fieles y esta es la tradición que aspiramos transmitir a nuestros alumnos mediante los mejores medios humanos y técnicos disponibles, que funden la mayor profundidad intelectual y la más consecuente vida vivida en justicia que -como lo dice Pieper-es la forma de vivir en verdad con el prójimo. 